3 Schainuck LI, Fouty R, Cutler RE. Emphysematous pyelonephritis. A new case and review of previous observations. Am f Med 1968;44:134-9.

4 Evanoff GV, Thompson CS, Foley R, Weinman EJ.

Evanoff GV, Thompson CS, Foley R, Weinman EJ. pyelonephritis and emphysematous pyelitis. Am $f \mathrm{Med}$ 1987;83:149-54.
5 Bohlman ME, Sweren BS, Khazan R, et al. Emphysematous pyelitis and emphysematous pyelonephritis characterised by computerised tomography. South Med f 1991;84: 1438-43.

\title{
Affective incontinence in a young adult
}

\author{
S Fazel, M Elphick
}

A 32-year-old woman was brought by ambulance to Accident and Emergency at $08.30 \mathrm{~h}$. She had been found asleep in a car by a man walking his dog at $07.00 \mathrm{~h}$. There was a vacuum cleaner hose carefully connected from the exhaust through a small opening in one of the windows. When she was found, the engine had been switched off. Petrol was still present in the car indicating that at some point for some reason, accidental or otherwise, the engine had stopped working. A suicide note was found in the car possibly written between midnight and $05.00 \mathrm{~h}$ that morning. An ambulance picked her up at $07.20 \mathrm{~h}$ and started administration of $100 \%$ oxygen.

On arrival in Accident and Emergency, the patient was confused, uncommunicative and drowsy with a Glasgow Coma Score of 14. Physical examination was unremarkable and no focal neurology was elicited. Plasma carboxyhaemoglobin was within the normal range (less than $2 \%$ ) and oxygen was discontinued. Routine blood tests were normal apart from a moderate leucocytosis $\left(17.5 \times 10^{6} / 1\right)$. She was admitted for observation, and transferred to a psychiatric unit for further assessment and management.

Her behaviour was grossly disturbed. In the first few days of her admission, she urinated on the floor three times, and was verbally aggressive. She remained disoriented in time and place, and demonstrated poor memory and poverty of thought content. Her speech was slurred and she answered all questions with "Don't know". To the question, "How many legs does a cow have?", she answered "eight". She was unable to read the clock, and could not reliably remember how many children she had or recognise them from photographs. She had experienced recent stressful life events - marital strife, debts of $£ 6000$, an unplanned pregnancy from a minor, temporary custody of her children by her husband, and an upcoming court case against her on a charge of GBH. She had rendered her husband partially deaf after striking him with a hammer.

Computed tomography (CT) and magnetic resonance imaging (MRI) subsequently demonstrated evidence of widespread bilateral damage to white matter around the basal ganglia. Neuropsychological testing confirmed significant deterioration in intellectual function with an IQ score of 62 and a Mini-Mental State Examination score of 16/30.

Oxfordshire Mental Healthcare NHS Trust, Elms Clinic, Oxford Road, Banbury OX16 9AL, UK

S Fazel

M Elphick

Accepted 24 October 1997

\section{Questions}

1 What is the most likely diagnosis?

2 What is the differential diagnosis?

3 What are the neuropsychiatric sequelae of this condition? 
Answers

QUESTION 1

Acute carbon monoxide (CO) poisoning. The CT and MRI findings of white matter damage around the basal ganglia is consistent with this diagnosis.

QUESTION 2

A presumptive diagnosis of hysteria was initially made in this case. In support of a dissociative disorder was a clear association with recent stressful life events, and its sudden onset. Her approximate answer to the question of "How many legs does a cow have?" suggested features in common with the hysterical dissociative reaction known as Ganser syndrome. Another possibility is that she was malingering, possibly contributed to by her upcoming court case. Drug intoxication was not suggested by her history and a drug screen on admission was negative.

QUESTION 3

Both treated and untreated cases of $\mathrm{CO}$ poisoning can have delayed neurological sequelae. This probably occurs because of late demyelination occuring secondary to hypoxic damage. ${ }^{2}$ Neuropsychiatric consequences of acute $\mathrm{CO}$ poisoning are characterised by disorientation and confusion with slowed speech and thought processes reduced. A characteristic triad of mental deterioration, urinary incontinence and gait abnormalities is found in those with severe poisoning. ${ }^{3}$ Enduring sequelae have been studied in survivors after three years; $43 \%$ showed impaired memory, $33 \%$ personality change, and $11 \%$ were left with gross neuropsychiatric damage. The constellation of irritability, verbal aggressiveness, impulsivity and moodiness found in these individuals has been termed 'affective incontinence'.

\section{Discussion}

Although the carboxyhaemoglobin concentration was normal on admission, the timing of events needs to be considered in relation to the half-life of carboxyhaemoglobin. When breathing normal air at atmospheric pressure, the half-life of carboxyhaemoglobin is $250 \mathrm{~min}$ utes. However, on breathing pure oxygen, it drops to 50 minutes. 5 Thus, because she received $100 \%$ oxygen while in the ambulance (70 minutes) and in casualty before her blood was taken (40 minutes), she could have

1 Silver DAT, Cross M, Fox B, Paxton RM. Computed tomography of the brain in acute carbon monoxide poisoning. Clin Radiol 1996;51:480-3.

2 Ginsberg MD. Carbon monoxide intoxication. Clinical features, neuropathology and mechanisms of injury. Clin Toxicol 1985;23:281-8.

3 Choi IS. Delayed neurologic sequelae in carbon monoxide intoxication. Arch Neurol 1983;40:433-5.

4 Smith JS, Brandon S. Morbidity from acute carbon monoxide poisoning at three-year follow-up. BMF 1973;1:318-21.

5 Pace N, Strajman E, Walker EL. Acceleration of carbon monoxide elimination in man by high pressure oxygen. Science 1950;111:652-4.
Commonest neuropsychiatric sequelae of CO poisoning

memory impairmen

- intellectual deterioration

- personality change

- gait disturbance

- urinary incontinence

- extrapyramidal disturbance

Box 1

\section{Poor prognostic factors in $\mathrm{CO}$} poisoning

- altered consciousness at presentation

advanced age

- metabloic acidosis

- abnormalities on CT or MRI scans

Box 2

reached a peak of $30-60 \%$ concentration of carboxyhaemoglobin shortly after her suicide note was written (between midnight and 05.00 h) and yet still have had a normal carboxyhaemoglobin concentration when tested.

Hyperbaric oxygen treatment is widely recommended for cases of $\mathrm{CO}$ poisoning with acute neurological symptoms. ${ }^{67}$ However evidence for its effectiveness is mainly based on retrospective case series, as a randomised controlled trial is probably not feasible in severe cases for ethical reasons. For this reason, it is not clear whether hyperbaric oxygen therapy actually reduces the frequency of delayed neurological sequalae in severe poisoning.

A recent review article has highlighted pitfalls that can lead to a missed diagnosis of CO poisoning including the presence of underlying chronic metabolic conditions. ${ }^{8}$ This case demonstrates that $\mathrm{CO}$ poisoning may remain undiagnosed if the timing of events is not taken into account, and carboxyhaemoglobin levels can be significantly underestimated in patients who have received $100 \%$ oxygen prior to blood testing.

\section{Final diagnosis}

Acute carbon monoxide poisoning.

Keywords: carbon monoxide poisoning

6 Thom SR. Hyperbaric oxygen therapy, a committee report. Undersea and Hyperbaric Medical Society, 1992.

7 Thom SR, Taber RL, Mendiguren II, et al. Delayed neuropsychologic sequelae after carbon monoxide poisoning. Prevention by treatment with hyperbaric oxygen. Ann Emerg Med 1995;25:474-80.

8 Balzan MV, Agius G, Debono AG. Carbon monoxide poisoning: easy to treat but difficult to recognise. Postgrad Med $\mathcal{~ f ~ 1 9 9 6 ; 7 2 : 4 7 0 - 3 . ~}$ 